\title{
METODE BENTUK NORMAL PADA PENYELESAIAN PERSAMAAN DUFFING
}

\author{
LIDYA PRATIWI, MAHDHIVAN SYAFWAN, RADHIATUL HUSNA \\ Program Studi Matematika, \\ Fakultas Matematika dan Ilmu Pengetahuan Alam, Universitas Andalas, \\ Kampus UNAND Limau Manis Padang, Indonesia, \\ email : lidyapratiwi1101@gmail.com
}

\begin{abstract}
Abstrak. Pada paper ini dibahas metode bentuk normal pada persamaan diferensial biasa non-linier orde 2 dan secara khusus diterapkan pada penyelesaian persamaan Duffing. sistematis untuk mendapatkan bentuk normal dari persamaan diferensial. Dengan menggunakan metode bentuk normal didapatkan solusi analitik dari persamaan Duffing yang kemudian dibandingkan dengan solusi numeriknya. Hasil perbandingan antara solusi analitik dan numerik menunjukkan kesesuaian yag cukup baik.

Kata Kunci: Persamaan Duffing, metode bentuk normal, transformasi koordinat
\end{abstract}

\section{Pendahuluan}

Persamaan diferensial merupakan suatu persamaan matematika yang memuat fungsi dan turunannya. Pada persamaan diferensial terdapat klasifikasi yaitu persamaan diferensial linier dan persamaan diferensial non-linier. Persamaan diferensial dikatakan linier jika variabel-variabel tak-bebasnya muncul dalam bentuk linier. Jika tidak demikian, maka persamaan diferensial tersebut dikatakan non-linier. Turunan tertinggi yang muncul pada persamaan diferensial disebut orde dari persamaan diferensial tersebut.

Suatu persamaan diferensial linier dan non-linier dapat diubah menjadi bentuk yang paling sederhana sedemikian sehingga solusinya dapat ditentukan dengan mudah. Persamaan dengan bentuk yang paling sederhana ini dinamakan bentuk normal (normal form) dari persamaan diferensial tersebut, sedangkan metode yang digunakan untuk menyederhanakan persamaan tersebut dinamakan metode bentuk normal [7]. Pada metode bentuk normal ini, suatu transformasi koordinat dikonstruksi secara sistematis untuk mendapatkan bentuk normal dari persamaan diferensial.

Dalam paper ini akan dibahas persamaan diferensial non-linier. Salah satu contoh dari persamaan diferensial non-linier adalah persamaan Duffing yang diberikan oleh [7].

$$
\ddot{u}+\omega^{2} u=\alpha u^{3}
$$

dimana $u(t)$ merepresentasikan perpindahan benda pada waktu $t, \omega$ menyatakan tingkat kekakuan (stiffness) benda, dan $\alpha$ merupakan koefisien suku non-linier yang 
bernilai kecil (disebut parameter perturbasi). Persamaan Duffing merupakan persamaan diferensial non-linier orde dua yang menggambarkan osilator dengan ketaklinieran berpangkat tiga. Persamaan Duffing digunakan oleh banyak peneliti sebagai suatu pendekatan model dalam banyak sistem fisik. Salah satu aplikasi dari persamaan Duffing tersebut adalah pada weak signal detection [7]. Persamaan Duffing diperkenalkan oleh seorang insinyur Jerman yang bernama George Duffing pada tahun 1918 [6].

Persamaan Duffing ini menjadi sangat menarik untuk dikupas lebih dalam karena persamaan tersebut memiliki solusi periodik, yaitu solusi yang merepresentasikan suatu fenomena yang terjadi secara berulang. Pembahasan pada paper ini mengeksplorasi kembali kajian pada referensi [7] dengan menambahkan pembahasan tentang perbandingan solusinya secara numerik.

\section{Konstruksi Awal Metode Bentuk Normal}

Dalam paper ini akan dijelaskan konstruksi awal dari metode bentuk normal pada persamaan diferensial biasa non-linier orde dua berikut:

$$
\ddot{u}+\omega^{2} u=f(u, \dot{u}),
$$

dimana $f(u, \dot{u})$ dapat dijabarkan dalam bentuk deret pangkat terhadap $u$ dan $\dot{u}$. Selanjutnya persamaan $(2.1)$ dengan $f(u, \dot{u})=0$ disebut sistem unpertubed, sedangkan untuk $f(u, \dot{u}) \neq 0$ disebut sistem pertubed. Asumsikan persamaan (2.1) mempunyai titik keseimbangan $u=0$ dan $\dot{u}=0$.

Persamaan (2.1) dapat diubah menjadi sistem persamaan diferensial orde satu dengan memisalkan

$$
x_{1}=u \text { dan } x_{2}=\dot{u},
$$

sehingga diperoleh

$$
\begin{aligned}
& \dot{x_{1}}=x_{2}, \\
& \dot{x_{2}}=f\left(x_{1}, x_{2}\right)-\omega^{2} x_{1} .
\end{aligned}
$$

Untuk sistem unperturbed, yaitu ketika $f\left(x_{1}, x_{2}\right)=0$, sistem (2.3)-(2.4) menjadi

$$
\begin{aligned}
& \dot{x_{1}}=x_{2}, \\
& \dot{x_{2}}=-\omega^{2} x_{1} .
\end{aligned}
$$

Sistem (2.5) dapat ditulis dalam bentuk matriks sebagai berikut:

$$
\left[\begin{array}{c}
\dot{x_{1}} \\
\dot{x_{2}}
\end{array}\right]=\left[\begin{array}{cc}
0 & 1 \\
-\omega^{2} & 0
\end{array}\right]\left[\begin{array}{l}
x_{1} \\
x_{2}
\end{array}\right] \text {. }
$$

Selanjutnya tulis

$$
A=\left[\begin{array}{cc}
0 & 1 \\
-\omega^{2} & 0
\end{array}\right] .
$$

Perhatikan bahwa

$$
\begin{aligned}
\operatorname{det}(A-\lambda I) & =\lambda^{2}+\omega^{2}=0 \\
\Leftrightarrow \lambda & = \pm \sqrt{-\omega^{2}}= \pm i \omega .
\end{aligned}
$$


Dengan demikian sistem unperturbed (2.5) mempunyai sepasang nilai eigen imajiner murni, yaitu $\pm i \omega$, sehingga berdasarkan Subbab 2.4, sistem unperturbed (2.5) memiliki solusi periodik.

Ide utama dari metode bentuk normal adalah dengan memperkenalkan transformasi near-identity dari $x_{1}$ ke $y_{1}$ dan $x_{2}$ ke $y_{2}$ sebagai berikut:

$$
\begin{aligned}
& x_{1}=y_{1}+h_{1}\left(y_{1}, y_{2}\right), \\
& x_{2}=y_{2}+h_{2}\left(y_{1}, y_{2}\right),
\end{aligned}
$$

dengan $h_{1} \approx 0$ dan $h_{2} \approx 0$, kemudian substistusikan ke sistem (2.3)-(2.4) sehingga diperoleh persamaan yang sesederhana mungkin (disebut bentuk normal). Persamaan (2.7) dan (2.8) disebut transformasi near-identity karena $x_{1}(t)-y_{1}(t)$ dan $x_{2}(t)-y_{2}(t)$ bernilai kecil. Dengan menggunakan aturan rantai, turunan pertama dari persamaan (2.7) dan (2.8) terhadap $t$ menghasilkan

$$
\begin{aligned}
& \dot{x}_{1}=\dot{y}_{1}+\frac{\partial h_{1}\left(y_{1}, y_{2}\right)}{\partial y_{1}} \dot{y}_{1}+\frac{\partial h_{1}\left(y_{1}, y_{2}\right)}{\partial y_{2}} \dot{y}_{2}, \\
& \dot{x}_{2}=\dot{y}_{2}+\frac{\partial h_{2}\left(y_{1}, y_{2}\right)}{\partial y_{1}} \dot{y}_{1}+\frac{\partial h_{2}\left(y_{1}, y_{2}\right)}{\partial y_{2}} \dot{y}_{2}
\end{aligned}
$$

Persamaan (2.7)-(2.8) dan (2.9)-(2.10) kemudian disubstitusikan ke persamaan (2.3) dan (2.4), sehingga diperoleh

$$
\dot{y}_{1}=y_{2}+h_{2}-\frac{\partial h_{1}}{\partial y_{1}} \dot{y}_{1}-\frac{\partial h_{1}}{\partial y_{2}} \dot{y}_{2}
$$

dan

$$
\dot{y}_{2}=-w^{2} y_{1}-w^{2} h_{2}+f\left(y_{1}+h_{1}, y_{2}+h_{2}\right)-\frac{\partial h_{2}}{\partial y_{1}} \dot{y}_{1}-\frac{\partial h_{2}}{\partial y_{2}} \dot{y}_{2} .
$$

Selanjutnya, $h_{1}$ dan $h_{2}$ dipilih sedemikian sehingga persamaan (2.11) dan (2.12) memiliki bentuk yang paling sederhana. Hal ini dapat diuraikan dalam beberapa langkah. Pertama, uraikan $f\left(x_{1}, x_{2}\right)$ menjadi

$$
f\left(x_{1}, x_{2}\right)=\Sigma_{n=1}^{N} f_{n}\left(x_{1}, x_{2}\right),
$$

dimana $f_{n}$ adalah polinomial derajat $n$ dalam $x_{1}$ dan $x_{2}$. Kemudian pilih $h_{1}$ dan $h_{2}$ untuk menyederhanakan suku-suku yang dihasilkan dari polinomial berorde terendah $f_{m}\left(x_{1}, x_{2}\right)$, dimana $m \geq 2$, pada $f\left(x_{1}, x_{2}\right)$. Langkah selanjutnya, pilih kembali suatu transformasi near-identity untuk menyederhanakan suku-suku polinomial berderajat $m+1$, dan seterusnya.

Karena sistem unperturbed (2.5) mendeskripsikan suatu getaran isolasi, maka sistem tersebut dapat diekspresikan sebagai suatu persamaan bernilai kompleks. Perhatikan bahwa persaman karakteristik dari (2.1) ketika $f=0$ adalah

$$
r^{2}+\omega^{2}=0 \Leftrightarrow r= \pm i \omega .
$$

Karena $r$ bernilai kompleks, maka solusi dari persamaan (2.1) ketika $f=0$ dapat ditulis sebagai

$$
u=B e^{i \omega t}+\bar{B} e^{-i \omega t}
$$


dimana $B$ adalah suatu konstanta kompleks dan $\bar{B}$ adalah kompleks konjugat dari $B$. Dari persamaan (2.15), diperoleh

$$
\dot{u}=i \omega\left(B e^{i \omega t}-\bar{B} e^{-i \omega t}\right) .
$$

Ketika $f \neq 0$, solusi dari persamaan (2.1) tetap ditulis dalam bentuk (2.15) dan memenuhi kendala (2.16). Kemudian dengan memisalkan $\xi(t)=B e^{i \omega t}$, maka persamaan (2.15) dan (2.16) menjadi

$$
\begin{aligned}
& u=\xi(t)+\bar{\xi}(t), \\
& \dot{u}=i \omega[\xi(t)-\bar{\xi}(t)] .
\end{aligned}
$$

Penyelesaian dari persamaan (2.17) dan (2.18) untuk $\xi$ da $\bar{\xi}$ adalah

$$
\xi=\frac{1}{2}\left(u-\frac{i}{\omega} \dot{u}\right),
$$

dan

$$
\bar{\xi}=\frac{1}{2}\left(u+\frac{i}{\omega} \dot{u}\right) .
$$

Selanjutnya dari persamaan (2.19) diperoleh turunan pertamanya sebagai berikut:

$$
\dot{\xi}=\frac{1}{2}\left(\dot{u}-\frac{i}{\omega} \ddot{u}\right) .
$$

Dengan mensubstitusikan persamaan (2.1) ke persamaan (2.21), diperoleh

$$
\dot{\xi}=\frac{1}{2} i \omega\left(u-\frac{i}{\omega} \dot{u}\right)-\frac{i}{2 \omega} f(u, \dot{u}) .
$$

Dengan menggunakan persamaan (2.17) dan (2.18), maka persamaan (2.22) menjadi

$$
\dot{\xi}=i \omega \xi-\frac{i}{2 \omega} f[\xi+\bar{\xi}, i \omega(\xi-\bar{\xi})] .
$$

Pada bab selanjutnya akan ditinjau secara khusus persamaan Duffing, yaitu untuk $f=\alpha u^{3}$.

\section{Penyelesaian Persamaan Duffing dengan menggunakan Metode Bentuk Normal}

Pandang kembali persamaan Duffing

$$
\ddot{u}+\omega^{2} u=\alpha u^{3} .
$$

Dengan melihat bentuk umum pada persamaan (2.1), maka pada kasus ini $f=\alpha u^{3}$. Dengan demikian persamaan (2.23) menjadi

$$
\begin{aligned}
\dot{\xi} & =i \omega \xi-\frac{i}{2 \omega} \alpha u^{3} \\
& =i \omega \xi-\frac{i \alpha}{2 \omega}(\xi+\bar{\xi})^{3} .
\end{aligned}
$$

Selanjutnya kenakan transformasi near-identity dari $\xi$ ke $\eta$ yang berbentuk

$$
\xi=\eta+h(\eta, \bar{\eta}),
$$


dengan $h \approx 0$, ke persamaan (3.2), sehingga diperoleh

$$
\dot{\eta}=i \omega \eta+i \omega h-\frac{\partial h}{\partial \eta} \dot{\eta}-\frac{\partial h}{\partial \bar{\eta}} \dot{\bar{\eta}}-\frac{i \alpha}{2 \omega}(\eta+h+\bar{\eta}+\bar{h})^{3} .
$$

Karena kenonlinieran dari persamaan (3.4) bertipe kubik, maka $h$ diasumsikan sebagai orde ketiga dalam $\eta$ dan $\bar{\eta}$, yaitu

$$
h=\Lambda_{1} \eta^{3}+\Lambda_{2} \eta^{2} \bar{\eta}+\Lambda_{3} \eta \bar{\eta}^{2}+\Lambda_{4} \bar{\eta}^{3}+\ldots,
$$

lalu $\Lambda_{i}$ dipilih sedemikian sehingga persamaan (3.4) menjadi bentuk normal.

Sebagai langkah pertama, eliminasi $\dot{\eta}$ dan $\dot{\bar{\eta}}$ pada ruas kanan persamaan (3.4). Hal ini dapat dilakukan dengan iterasi. Untuk aproksimasi pertama dapat dipilih

$$
\dot{\eta}=i \omega \eta \text { dan } \dot{\bar{\eta}}=-i \omega \bar{\eta}
$$

Kemudian $\dot{\eta}$ dan $\dot{\bar{\eta}}$ pada ruas kanan persamaan (3.4) diganti dengan persamaan (3.6) dan gunakan persamaan (3.5), sehingga diperoleh

$$
\begin{aligned}
\dot{\eta}= & i \omega \eta-i \omega\left(2 \Lambda_{1}+\frac{\alpha}{2 \omega^{2}}\right) \eta^{3}-\frac{3 i \alpha}{2 \omega} \eta^{2} \bar{\eta}+i \omega\left(2 \Lambda_{3}-\frac{3 \alpha}{2 \omega^{2}}\right) \eta \bar{\eta}^{2} \\
& +i \omega\left(4 \Lambda_{4}-\frac{\alpha}{2 \omega^{2}}\right) \bar{\eta}^{3}+\ldots
\end{aligned}
$$

Selanjutnya untuk mengeliminasi suku-suku yang memuat $\eta^{3}, \eta \bar{\eta}^{2}$, dan $\bar{\eta}^{3}$, maka haruslah berlaku

$$
\Lambda_{1}=-\frac{\alpha}{4 \omega^{2}}, \quad \Lambda_{3}=\frac{3 \alpha}{4 \omega^{2}}, \quad \Lambda_{4}=\frac{\alpha}{8 \omega^{2}} .
$$

Namun, karena $\Lambda_{2}$ tidak muncul pada persamaan (3.7), maka suku yang melibatkan $\eta^{2} \bar{\eta}$ tidak dapat dieliminasi. Suku ini disebut suku resonansi (resonance term). Akibatnya, pada aproksimasi kedua, bentuk yang paling sederhana untuk $\dot{\eta}$ adalah

$$
\dot{\eta}=i \omega \eta-\frac{3 i \alpha}{2 \omega} \eta^{2} \bar{\eta}
$$

Substitusikan persamaan (3.3) dan(3.5) ke persamaan (2.17) dan (2.18), kemudian gunakan (3.8) dan tetapkan $\Lambda_{2}=0$, maka diperoleh

$$
u=\eta+\bar{\eta}-\frac{\alpha}{8 \omega^{2}}\left(\eta^{3}+\bar{\eta}^{3}\right)+\frac{3 \alpha}{4 \omega^{2}}\left(\eta \bar{\eta}^{2}+\eta^{2} \bar{\eta}\right)+\ldots
$$

dimana $\eta$ diberikan oleh persamaan (3.9). Misalkan solusi untuk $\eta$ diberikan oleh

$$
\eta=A(t) e^{i \omega t}
$$

dimana $\omega$ merupakan frekuensi alami dari sistem dan $A$ merupakan fungsi kompleks terhadap waktu. Substitusikan (3.11) ke dalam persamaan (3.9), maka diperoleh

$$
\dot{A}=-\frac{3 i \alpha}{2 \omega} A^{2} \bar{A} .
$$

Selanjutnya, substitusikan (3.11) ke persamaan (3.10), maka didapatkan

$$
\begin{aligned}
u= & A e^{i \omega t}+\bar{A} e^{-i \omega t}-\frac{\alpha}{8 \omega^{2}}\left(A^{3} e^{3 i \omega t}+\bar{A}^{3} e^{-3 i \omega t}\right) \\
& +\frac{3 \alpha}{4 \omega^{2}}\left(A^{2} \bar{A} e^{i \omega t}+\bar{A}^{2} A e^{-i \omega t}\right)+\ldots
\end{aligned}
$$


Karena $A$ menyatakan fungsi kompleks, maka $A$ dapat dinyatakan dalam bentuk polar

$$
A=a e^{i \beta}
$$

dimana $a$ dan $\beta$ merupakan fungsi terhadap $t$. Dengan demikian persamaan (3.13) menjadi

$$
u=\left(2 a+\frac{3 \alpha}{2 \omega^{2}} a^{3}\right) \cos (\beta+\omega t)-\frac{\alpha a^{3}}{4 \omega^{2}} \cos (3 \beta+3 \omega t)+\ldots
$$

Substitusikan persamaan (3.14) ke dalam persamaan (3.15), maka berlaku

$$
\dot{a}+i a \dot{\beta}=-\frac{3 i \alpha}{2 \omega} a^{3} .
$$

Kemudian pisahkan bagian riil dan imajiner pada persamaan (3.16), maka didapatkan

$$
\begin{aligned}
& \dot{a}=0, \\
& \dot{\beta}=-\frac{3 \alpha}{2 \omega} a^{2} .
\end{aligned}
$$

Solusi dari persamaan (3.17)-(3.18) diberikan oleh

$$
\begin{aligned}
& a=C_{1}, \\
& \beta=-\frac{3 \alpha}{2 \omega} C_{1}^{2} t+C_{2},
\end{aligned}
$$

dimana $C_{1}, C_{2}$ suatu konstanta riil sebarang. Ganti nilai a dan $\beta$ pada persamaan (3.15) dengan (3.19) dan (3.20), maka diperoleh

$$
\begin{aligned}
u= & \left(2 C_{1}+\frac{3 \alpha}{2 \omega^{2}} C_{1}^{3}\right) \cos \left(-\frac{3 \alpha}{2 \omega} C_{1}^{2} t+C_{2}+\omega t\right) \\
& -\frac{\alpha C_{1}^{3}}{4 \omega^{2}} \cos \left(-\frac{9 \alpha}{2 \omega} C_{1}^{2} t+3 C_{2}+3 \omega t\right)+\ldots
\end{aligned}
$$

yang merupakan solusi umum dari persamaan Duffing (3.1).

\section{Perbandingan dengan Solusi Numerik}

Pada subbab ini, solusi dari persamaan Duffing yang diperoleh dari metode bentuk normal, yang diberikan oleh persamaan (3.21), akan dibandingkan dengan solusi numeriknya. Karena solusi (3.21) muncul dalam bentuk deret, maka dalam implementasinya, solusi numerik akan dibandingkan dengan dua suku pertama dari solusi (3.21), yaitu

$u=\left(2 C_{1}+\frac{3 \alpha}{2 \omega^{2}} C_{1}^{3}\right) \cos \left(-\frac{3 \alpha}{2 \omega} C_{1}^{2} t+C_{2}+\omega t\right)-\frac{\alpha C_{1}^{3}}{4 \omega^{2}} \cos \left(-\frac{9 \alpha}{2 \omega} C_{1}^{2} t+3 C_{2}+3 \omega t\right)$.

Untuk penyelesaian numerik, terlebih dahulu ubah persamaan Duffing (3.1), menjadi sistem persamaan diferensial orde 1 dengan memisalkan $\dot{u}(t)=p(t)$, sehingga diperoleh

$$
\begin{aligned}
& \dot{u}=p, \\
& \dot{p}=\alpha u^{3}-\omega^{2} u .
\end{aligned}
$$


Akibatnya pada saat $t=0$ diperoleh

$$
\begin{aligned}
u(0)= & \left(2 C_{1}+\frac{3 \alpha}{2 \omega^{2}} C_{1}^{3}\right) \cos \left(C_{2}\right)-\frac{\alpha C_{1}^{3}}{4 \omega^{2}} \cos \left(3 C_{2}\right), \\
p(0)= & \dot{u}(0)=-\left(2 C_{1}+\frac{3 \alpha C_{1}^{2}}{2 \omega^{2}}\right) \sin \left(-C_{2}\right)\left(-\omega+\frac{3 \alpha C_{1}^{2}}{2 \omega}\right) \\
& +\frac{\alpha C_{1}^{3}}{4 \omega^{2}}\left(-3 C_{2}\right)\left(-3 \omega+\frac{9 \alpha C_{1}^{2}}{2 \omega}\right),
\end{aligned}
$$

yang dapat digunakan sebagai syarat awal dari sistem (4.1). Selanjutnya sistem (3.1) dengan syarat awal (4.4) diimplementasikan ke rumus iterasi Runge-Kutta dengan ukuran langkah $h=0.1$.

Sebagai contoh ilustrasi, gunakan nilai-nilai berikut:

$$
\alpha=0.01, \quad \omega=0.5, \quad C_{1}=C_{2}=1 .
$$

Kemudian untuk nilai-nilai (4.4), diperoleh $u(0)=1.122922675$ dan $p(0)=$ $-0,127224154$. Hasil solusi numerik dan perbandingannya dengan hampiran solusi analitik (4.1) diberikan oleh Gambar 1. Dari gambar tersebut dapat dilihat bahwa hampiran solusi analitik dan solusi numerik untuk nilai-nilai (4.4) menunjukkan kesesuaian yang cukup baik.

Selanjutnya, galat dari hampiran solusi analitik yang didefinisikan sebagai selisih antara solusi (4.1) dan solusi numerik untuk nilai-nilai (4.4) diberikan oleh Gambar 2. Dari gambar dapat dilihat bahwa galat solusi analitik masih cukup besar, terutama untuk nilai $t$ yang semakin besar, dan bernilai kecil di sekitar interval $10 \leq t<20$. Galat ini dapat diperkecil jika perhitungan metode normal melibatkan suku-suku selanjutnya.

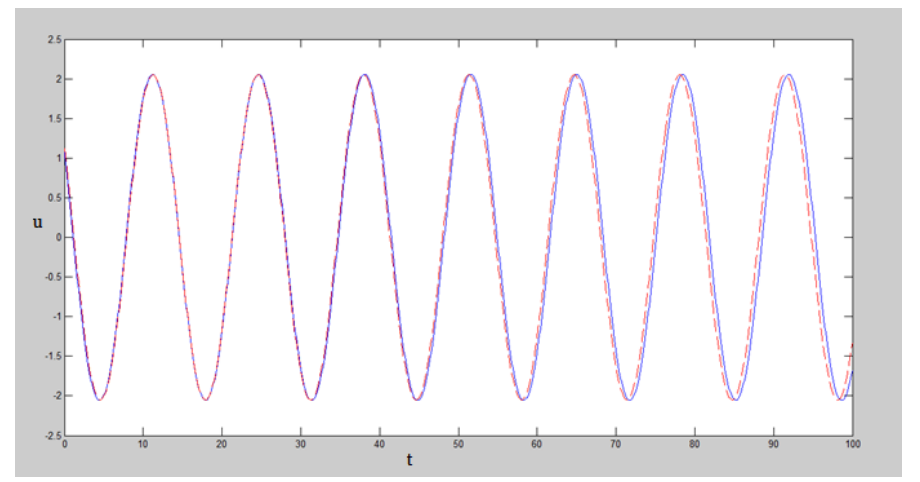

Gambar 1. Perbandingan solusi numerik (biru) dan hampiran solusi analitik (merah) yang diperoleh dari metode bentuk normal [persamaan (4.1)] untuk $\alpha=0.01, \omega=0.5, C_{1}=C_{2}=1$. 


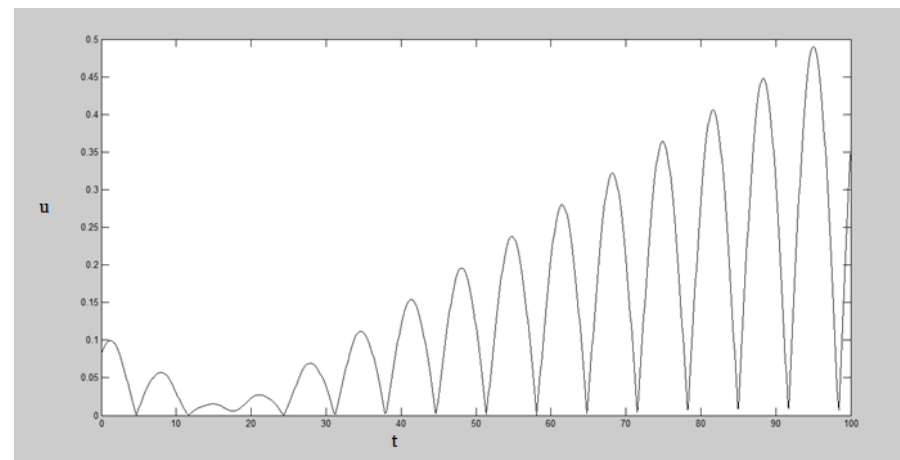

Gambar 2. Galat solusi analitik yang diperoleh dari metode bentuk normal [persamaan (4.1)] untuk $\alpha=0.01, \omega=0.5, C_{1}=C_{2}=1$

\section{Kesimpulan}

Dengan menggunakan metode bentuk normal, diperoleh solusi umum dari persamaan Duffing yang diberikan oleh

$$
\begin{aligned}
u= & \left.\left(2 C_{1}+\frac{3 \alpha}{2 \omega^{2}} C_{1}^{3}\right) \cos \left(-\frac{3 \alpha}{2 \omega} C_{1}^{2} t+C_{2}\right)+\omega t\right) \\
& \left.-\frac{\alpha C_{1}^{3}}{4 \omega^{2}} \cos \left(-\frac{9 \alpha}{2 \omega} C_{1}^{2} t+3 C_{2}\right)+\omega t+3 \omega t\right),
\end{aligned}
$$

dengan $C_{1}$ dan $C_{2}$ suatu konstanta sebarang.

Solusi analitik tersebut (sampai dua suku pertama) kemudian dibandingkan dengan solusi numerik yang diperoleh dengan menggunakan metode Runge-Kutta orde 4. Hasil perbandingan antara solusi analitik dan numerik menunjukkan kesesuaian yang cukup baik.

\section{Ucapan Terima kasih}

Penulis mengucapkan terima kasih kepada Bapak Dr. Dodi Devianto, Bapak Dr. Jenizon, dan Bapak Narwen, M.Si yang telah memberikan masukan dan saran sehingga paper ini dapat diselesaikan dengan baik.

\section{Daftar Pustaka}

[1] Anton, H. 1991. Aljabar Linier Elementer Edisi Kedelapan-Jilid 1. Erlangga, Jakarta.

[2] Boyce,William E and Richard C. Diprima. 2009. Elementary Differential Equations and Boundary Value Problems. Jhon Wiley and Sons, New York.

[3] D.G. Luenberger. 1979. Introduction to Dynamic Systems. John Wiley and Sons Inc, New York.

[4] Iserles, A. (2009). A First Course in the Numerical Analysis of Differential Equations. Cambridge University Press, Cambridge.

[5] Kovacic, Ivana and Michael J. Brennan. 2011. The Duffing Equation: Nonlinear Oscillators and their Behaviour. John Wiley and Sons, West Sussex. 
Metode Bentuk Normal pada Penyelesaian Persamaan Duffing 55

[6] Nayfeh, Ali Hasan. 2011. The Method of Normal Forms. Wiley-VCH, Weinheim.

[7] Tamimi, Z. A dan S. B. Waluya. 2014. Penyelesaian Persamaan Duffing Oscilator pada Aplikasi Weak Signal Detection menggunakan Metode Averaging. 37(2): $192-199$. 